\title{
Epidemia, controle e vigilância: das quarentenas analógicas à quarentena digital
}

\author{
Epidemics, control and surveillance: from analogue quarantine to digital \\ quarantine
}

\section{Rone Eleandro Santos*}

Resumo: No presente artigo analisamos como a ocorrência de epidemias de doenças contagiosas levaram o poder político e o conhecimento médico ao uso de diferentes técnicas e mecanismos para as enfrentar, como a instalação de quarentenas. Veremos como as epidemias de lepra e de peste e a atual pandemia de Covid-19 colocam em uso diferentes dispositivos e técnicas de controle e vigilância sobre os contaminados. A descoberta de que a restrição de movimento e o isolamento dos infectados diminui a disseminação de doenças contagiosas foi, e ainda é, uma das primeiras recomendações médicas na situação de epidemias. Nesse sentido, veremos como, das quarentenas antigas à quarentena atual, intensificamos ainda mais a vigilância sobre os corpos ao passarmos de um controle sobre a pele para um controle sob a pele.

Palavras-chave: Controle; Vigilância; Quarentena Analógica; Quarentena Digital

\begin{abstract}
In this article, we analyze how the occurrence of epidemics of contagious diseases led political power and medical knowledge to the use of different techniques and mechanisms to deal with them, such as the installation of quarantines. We will see how the leprosy and plague epidemics and the current Covid-19 pandemic put different control and surveillance devices and techniques on those contaminated to use. The discovery that restricting movement and isolating the infected reduces the spread of contagious diseases was, and still is, one of the first medical recommendations in the event of an epidemic. In this sense, we will see how, from the old quarantines to the current quarantine, we intensify the surveillance over the bodies even more when we move from a control over the skin to a control under the skin.
\end{abstract}

Keywords: Control; Surveillance; Analog Quarantine; Digital Quarantine

\section{Introdução}

Enquanto prática de separação entre pessoas que estão doentes das que não estão a quarentena foi usada primeiramente na Europa do final do século XIV. Cidades portuárias como Veneza, por exemplo, adotaram a regra de manter ancorado em alto mar navios que viessem de outros portos com suspeita de doenças contagiosas. Deveriam esperar quarenta dias de isolamento antes de poder descarregar as mercadorias ou ter permissão para que as pessoas desembarcassem. Seja no trabalho nos portos ou no convívio urbano essa prática foi muito usada ao longo do tempo até nossos dias. A atual pandemia do novo coronavírus, causador da doença que foi denominada Covid-19, demonstra como essa prática medieval ainda tem uso mesmo em um mundo altamente tecnológico e digitalizado como o nosso.

Tomado em sua forma e com suas características podemos dizer que a quarentena é uma tecnologia de controle e de vigilância? Podemos afirmar que as regras, as normas, as proibições e os procedimentos próprios da quarentena formam um conjunto de técnicas que

* Professor de Filosofia no Instituto Federal de Educação, Ciência e Tecnologia do Sudeste de Minas Gerais, Muriaé, MG. Email: rone.res@live.com ORCID: https://orcid.org/0000-0002-6133-0914 
visam diminuir ou eliminar a doença, ao mesmo tempo em que realiza a vigilância e o controle sobre os corpos e mentes dos indivíduos. Na sua essência o modus operandi da quarentena medieval e da quarentena contemporânea permanece o mesmo. Contudo, a presente situação de pandemia de Covid-19 e a instalação de quarentenas em diversos países conta com o diferencial do uso da internet e de tecnologias digitais. Estas, por meio de seus dispositivos e de seus artefatos, potencializam e aumentam de forma exponencial o poder de controle, de vigilância e de rastreamento das pessoas infectadas nos países em que estas tecnologias de informação encontram-se disseminadas.

No presente artigo veremos como em ocasiões de grandes pandemias foram implantados modelos diferenciados de controle dos indivíduos. A primeira parte expõe como para lidar com a difusão da lepra foi instalado a prática de exclusão do leproso, enquanto no combate contra a peste se realizou a inclusão do pestífero. Na segunda parte analisaremos como o modelo atual realiza uma mescla de procedimentos antigos de quarentena associados ao uso de dispositivos digitais interconectados via Internet das Coisas (IoT), Big Data, Inteligência Artificial (IA), internet das nuvens e sensores de captação de dados. 0 que chamaremos de modelo da hiperconexão do infectado. Todos esses modelos seguem de perto a ideia do Panóptico como mecanismo de supervisão generalizada. Seja no conceito clássico de panoptismo ou na versão atual de um panoptismo digital.

\section{Quarentenas analógicas: a exclusão do leproso e a inclusão do pestífero}

No famoso capítulo de Vigiar e Punir (1975) dedicado ao estudo do Panóptico Foucault realiza uma meticulosa descrição das medidas administrativas e policiais, amplamente adotadas em fins do século XVII, em caso de epidemia de peste. Na economia de sua descrição é pontuado um regime de policiamento espacial que segue uma escala hierárquica de vigilância. Após o fechamento da cidade é proibido a circulação, cada quarteirão é entregue a um intendente, cada rua fica a cargo de um síndico que fecha pelo lado de fora todas as casas e entrega as chaves ao intendente até o fim da quarentena ${ }^{1}$. Para que todos os moradores tenham acesso a mantimentos para se alimentarem foi elaborado um complexo sistema de fornecimento de provisões. Qualquer saída não permitida poderia ser punida com prisão e até mesmo a morte. Mas, se absolutamente necessário, era permitido sair das casas desde que fosse seguido um esquema de turnos para evitar encontros e aglomerações nas ruas. Somente tinham liberdade de circulação os intendentes, os síndicos, os soldados da guarda e os "corvos" - grupo de pessoas consideradas vis e abjetas, que poderiam ser abandonados à morte, mas que faziam o trabalho essencial de ir de casa em casa cuidar dos doentes, pegar os mortos para serem enterrados e efetuar a limpeza e descontaminação. Nesse cenário vemos que todo o espaço é recortado, imóvel e fixado; a cada indivíduo é reservado um lugar ao qual deve se prender pois, caso se desloque e se ponha em movimento corre o risco de vida, ou por contaminação ou por punição².

É executada uma tarefa de inspeção constante por meio de diversos olhos que vasculham todas as partes. Soldados nas ruas, guardas nas portas, sentinelas nos postos de vigilância. Todo espaço é mapeado, esquadrinhado e observado. Todo evento não permitido, todo comportamento desviante e toda desobediência é anotada para ser relatada aos síndicos e aos intendentes. Mas os moradores também podem fiscalizar seus vigilantes e relatar suas queixas caso aqueles não estejam cumprindo corretamente seu trabalho. Todos os dias as casas são fiscalizadas, seus moradores deveriam aparecer nas janelas e uma chamada nominal era feita. 0 estado de saúde de todos os moradores era questionado e os habitantes deveriam dizer a verdade sob pena de morte se mentissem; se alguém não se apresentasse na janela

\footnotetext{
${ }^{1}$ FOUCAULT, Vigiar e Punir, 190.

${ }^{2}$ FOUCAULT, Vigiar e Punir, 190.
} 
deveriam dizer o motivo, a depender da resposta se sabia se mentiam ou diziam a verdade. "Cada um trancado em sua gaiola, cada um à sua janela, respondendo a seu nome e se mostrando quando é perguntado, é a grande revista dos mortos e dos vivos"3.

Para manter o funcionamento da quarentena eram feitos registros minuciosos que eram transformados em relatórios constantemente entregues a superiores hierárquicos até chegar nas mãos do prefeito. Tudo era anotado durante as visitas: os nomes, as idades, o sexo, a condição de saúde, as doenças, as mortes, as reclamações, as irregularidades. Intendentes e magistrados tinham acesso aos relatórios e às informações médicas de cada habitante. Aos doentes era destinado um médico, um boticário e um confessor que deveriam responder diretamente aos magistrados e intendentes. Todos esses registravam e relatavam constantemente o estado de saúde dos vivos.

Esse espaço fechado, recortado, vigiado em todos os seus pontos, onde os indivíduos estão inseridos num lugar fixo, onde os menores movimentos são controlados, onde todos os acontecimentos são registrados, onde um trabalho ininterrupto de escrita liga o centro e a periferia, onde o poder é exercido sem divisão, segundo uma figura hierárquica contínua, onde cada indivíduo é constantemente localizado, examinado e distribuído entre os vivos, os doentes e os mortos - isso tudo constitui um modelo compacto do dispositivo disciplinar 4 .

$\mathrm{Na}$ quarentena vigilante implantada contra a peste quem se contamina divide o mesmo espaço com quem ainda está são. Infectados e não-infectados muitas vezes coabitam a mesma residência de modo que era difícil impedir a proliferação da doença e o aumento do número de casos. É desse modo que "contra a peste que é mistura, a disciplina faz valer seu poder que é de análise" 5 . No sonho médico e político da peste a quarentena realiza um modelo de controle que efetua a inclusão dos pestíferos dentro da cidade, em suas casas, junto de seus familiares. Essa mistura entre são e doente era acompanhada e controlada através dos dispositivos de exames, marcações, análises, contagens e relatórios. Um complexo mecanismo médico e político foi posto em funcionamento contra a epidemia de peste já que o doente não era posto para fora dos limites da cidade. A doença era combatida dentro dos muros através do tratamento dos infectados, do cuidado com os são e do enterro dos mortos. 0 modelo inclusivo do pestífero trabalha sobre a lógica da supervisão e do acompanhamento íntimo do desenrolar da epidemia. Algo muito diferente do modelo adotado para com a lepra.

0 procedimento medieval de diagnóstico e identificação da lepra seguia alguns procedimentos. Geralmente alguém que era diagnosticado como leproso passou por um sacerdote, por um médico e, em alguns povos, foi atendido por um barbeiro. Somente depois destas análises era feito o diagnóstico, emitindo um decreto que o declara saudável ou acometido de lepra. Por conta das consequências desse diagnóstico ele deveria ser muito criterioso e com farta descrição dos sintomas. Por ser uma doença causadora de deformidades físicas a simples constatação dessas já servia como comprovação de que se tratava de um leproso.

Após ser diagnosticado como leproso o indivíduo deveria passar por uma série de ritos religiosos que eram uma mescla de despedida, reconforto e súplica. Na sequência, ele era levado até os limites da cidade onde lhe eram recitado uma série de proibições e regras como: o impedimento de circular pela cidade, o dever de usar roupas de leprosos, o impedimento de confraternizar com outras pessoas a não ser que também sejam leprosos etc. Em seguida lhe era entregue seu enxoval identificatório: um capuz marrom ou cinza, sapatos de couro, um par de sinetas ou matracas para avisar as pessoas da proximidade, um copo, uma bengala, um

\footnotetext{
${ }^{3}$ FOUCAULT, Vigiar e Punir, 191.

${ }^{4}$ FOUCAULT, Vigiar e Punir, 192, destaque nosso.

${ }^{5}$ FOUCAULT, Vigiar e Punir, 192.
} 
par de lençóis, uma faca pequena e um prato $^{6}$. Sozinho e desamparado o leproso deveria caminhar em campo aberto, fora dos muros da cidade, fixando morada longe das pessoas não contaminadas. Ali ele viveria até sua morte e nunca mais poderia frequentar lugares públicos. Sempre que se aproximasse de caminhos públicos e de conjuntos populacionais em busca de comida deveria avisar as pessoas tocando a sineta.

Não se pode excluir como causa desse isolamento e exclusão compulsiva do leproso a vaga noção empírica das formas de contágio. Uma possível comprovação disso é a criação dos leprosários que deveriam ser instalados em locais distantes, elevados, arejados e ventilados. A criação de leprosários não melhorou muito a situação dos infectados, pelo contrário, aumentou ainda mais a discriminação e o medo para com os leprosos. Isso se deve em grande medida porque essas casas de tratamento eram vistas como cemitérios para vivos.

A forma de controle da lepra suscitou um modelo de exclusão por fechamento e encarceramento ou de banimento e exílio dos contaminados. Já a disciplina e a vigilância foram as táticas usadas para lidar com o modelo da peste que demandava um policiamento constante e o exame detalhado funcionando por inclusão e distribuição dos indivíduos supervisionados.

O leproso é visto dentro de uma prática da rejeição, do exílio-cerca; deixa-se que se perca lá dentro como numa massa que não tem muita importância diferenciar; os pestilentos são considerados num policiamento tático meticuloso onde as diferenciações individuais são os efeitos limitantes de um poder que se multiplica, se articula e se subdivide. 0 grande fechamento por um lado; o bom treinamento por outro. A lepra e sua divisão; a peste e seus recortes. Uma é marcada; a outra, analisada e repartida. 0 exílio do leproso e a prisão da peste não trazem consigo o mesmo sonho político. Um é o de uma comunidade pura, o outro, o de uma sociedade disciplinar. Duas maneiras de exercer poder sobre os homens, de controlar suas relações, de desmanchar suas perigosas misturas ${ }^{7}$.

No modelo medieval da exclusão do leproso todo infectado deveria ser rigorosamente separado dos não infectados e excluídos dos espaços de convivência comunitária no interior das cidades. Essas ações médicas e sanitárias tinham como objetivo realizar uma purificação do meio urbano. No modelo, usado no final do século XVII e início do XVIII, da inclusão do pestífero não se excluía o infectado, pelo contrário, ele era trazido para dentro dos espaços urbanos. 0 poder médico e político dividia a cidade em escalas espaciais diferenciadas onde todos os movimentos eram registrados, e tudo e todos eram vigiados e controlados de forma ininterrupta. "O momento da peste é o momento do policiamento exaustivo de uma população por um poder político, cujas ramificações capilares atingem sem cessar o próprio grão dos indivíduos, seu tempo, seu hábitat, sua localização, seu corpo"8.

Com a exclusão do leproso criou-se um modelo para lidar com o perigo da doença que criava um "fora", um "além-muro". Foi criado um "espaço exterior da morte", quer sejam os leprosários ou os campos fora da cidade, para onde indivíduos contaminados eram conduzidos à força. Eram levados para esses espaços para morrer. Com a inclusão do pestífero prevalece a análise dos infectados em espaços vigiados e controlados. A cidade empesteada era fechada, era declarada a quarentena, era implantada uma cadeia de vigilância hierarquizada e de exames contínuos que deveriam ser seguidos. É um poder médico e político que age por proximidade, que controla presenças e ausências, com o objetivo de gerir a vida e maximizar a saúde, e não mais para conduzir à morte.

\footnotetext{
${ }^{6}$ RICHARDS, The Medieval Leper and his Northern Heirs, 124.

${ }^{7}$ FOUCAULT, Vigiar e Punir, 192-193.

${ }^{8}$ FOUCAULT, Os anormais, 59.
} 
Nesses dois modelos a forma de lidar com epidemias tem suas especificidades, mas se encontram quanto ao uso da implantação de quarentenas e de isolamento social. Ora, ainda em nossos dias esses mesmos mecanismos são usados. Contudo, o uso generalizado de dispositivos tecnológicos e ferramentas digitais colocam elementos novos na forma de lidar com epidemias. A vigilância, o controle, o monitoramento do estado de saúde e da movimentação de indivíduos doentes, feita por meios tecnodigitais, caracteriza o modelo atual da hiperconexão do infectado. A seguir passaremos a tratar sobre esse modelo.

\section{Quarentena digital: a hiperconexão do infectado}

Os procedimentos e as técnicas adotadas nos sistemas de quarentenas durante epidemias de lepra e peste foram sendo melhoradas e adotadas pela prática médica. $\mathrm{Na}$ passagem do século XVIII para o XIX a nossa sociedade atravessou, segundo Foucault, o "umbral da modernidade biológica". Nesse momento o indivíduo e a espécie humana entram de vez nas estratégias e nos cálculos do poder político. Ocorre uma "estatização do biológico" quando a vida biológica e a saúde se tornam alvos centrais de um poder sobre a vida, de uma biopolítica. Para Foucault o biopoder é uma tecnologia política cujo alvo é a vida tomada a partir da multiplicidade de uma população. A biopolítica se caracteriza por ser uma gestão calculada do ingresso da vida natural no domínio da política. Está em seu escopo a formação de saberes que controlam e explicam e a aplicação de poderes que intervêm diretamente na regularização e controle dos indivíduos ${ }^{9}$.

Associado à biopolítica e agindo de forma complementar Foucault pensou o conceito de governamentalidade. De modo geral podemos dizer que a primeira age sobre os corpos individuais e o corpo social impondo regras, normas e procedimentos biológicos e médicos. Já a governamentalidade é uma chave de inteligibilidade, de um pano de fundo, de um campo de possibilidades a partir dos quais são pensadas as relações de poder. Ela é exercida sobre um conjunto de indivíduos através da ação governamental que opera através da estruturação dos possíveis campos de ação dos indivíduos. Exercer o poder sobre os outros é menos da ordem do cerceamento, do afrontamento entre adversários e do impedimento através de mecanismos legais e mais da ordem do governo das ações, da administração das eventualidades, da gestão dos possíveis riscos e perigos. 0 biopoder opera principalmente através de estados de dominação que atuam sobre a vida natural politicamente investida. Já a governamentalidade age por meio da combinação de técnicas de dominação e técnicas de si que pressupõe e necessita da existência de sujeitos livres ${ }^{10}$.

Contudo, a liberdade concedida a esses sujeitos está condicionada aos limites dados e controlados pelo poder político. Já em Vigiar e Punir Foucault antecipa o que viria a ser concebido como controle, estendendo a disciplina para além dos limites do modelo panóptico.

0 ponto ideal da penalidade hoje seria a disciplina infinita: um interrogatório sem termo, um inquérito que se prolongasse sem limite numa observação minuciosa e cada vez mais analítica, um julgamento que seja ao mesmo tempo a constituição de um processo nunca encerrado, o amolecimento calculado de uma pena ligada à curiosidade implacável de um exame, um procedimento que seja ao mesmo tempo a medida permanente de um desvio em relação a uma norma inacessível e o movimento assintótico que obriga a encontrá-la no infinito ${ }^{11 .}$

\footnotetext{
${ }^{9}$ CANDIOTTO, Entrevista: Foucault e a governamentalidade biopolítica.

${ }^{10}$ CANDIOTTO, Entrevista: Foucault e a governamentalidade biopolítica.

${ }^{11}$ FOUCAULT, Vigiar e Punir, 187.
} 
Gilles Deleuze retomou e reformulou esse esboço de uma sociedade de controle. Faz isso articulando a noção de biopoder de Foucault com a problemática do controle. De modo complementar pensou essa articulação ligada à ascensão das formas contemporâneas de tecnologia. 0 controle é um mecanismo inerente ao poder disciplinar: se controla o corpo, o tempo, o gesto, o trabalho, até mesmo a própria consciência. Se nas sociedades disciplinares o controle era exercido em instituições específicas - como as prisões, escolas, hospitais e casernas - nas sociedades contemporâneas ele ocorre no espaço aberto da sociedade. De fato, já em 1987 na conferência Qu'est-ce que l'acte de création? [O que é o ato de criação?], a noção de sociedades de controle aparece pela primeira vez na obra de Deleuze:

Um controle não é uma disciplina. Com uma estrada não se enclausuram pessoas, mas, ao fazer estradas, multiplicam-se os meios de controle. Não digo que esse seja o único objetivo das estradas, mas as pessoas podem trafegar até o infinito e 'livremente', sem a mínima clausura, e serem perfeitamente controladas. Esse é o nosso futuro ${ }^{12}$.

De acordo com Deleuze para cada tipo de sociedade existe seu correspondente tipo de máquina. Nas antigas sociedades de soberania prevalecia o uso de roldanas, alavancas e relógios. Nas sociedades disciplinares operavam as máquinas industriais e à vapor. Já as atuais sociedades de controle estão estreitamente ligadas aos computadores, à tecnologia de informação e a todo aparato digital. Desde metade do século passado o paradigma da máquina a vapor ou da máquina movida por combustíveis fósseis vem sendo substituída pela rede mundial de computadores, pela internet e pelo uso massivo de dados e algoritmos. Claramente isso implica em mudanças no modo como concebemos a relação espaço-tempo, o modo como apreendemos as mudanças, e a forma como nos relacionamos com a velocidade vertiginosa da vida cotidiana. Em um contexto de crise generalizada das instituições e de seus instrumentos de confinamento surgem novas formas de controle que operam de forma livre, estimulando a circulação e substituindo as antigas disciplinas. Desse modo, enfatiza, "estamos entrando nas sociedades de controle, que funcionam não mais por confinamento, mas por controle contínuo e comunicação instantânea"13.

Se nas sociedades disciplinares os sujeitos eram moldados dentro de espaços fechados, com as sociedades de controle ocorre uma flexibilização dos limites institucionais. Não é que deixam de existir a prisão, a escola, o hospital e outras instituições disciplinares, mas ocorre uma simbiose entre o dentro e o fora, entre o fechado e o aberto. Se antes a vigilância estava confinada ao interior dos espaços agora ela se expande aos espaços abertos buscando se generalizar e não mais ficar restrita a determinadas áreas. De fato, esse apagamento dos contornos das instituições leva a uma porosidade das fronteiras entre a interioridade e a exterioridade, entre o público e o privado. Basta quanto a isso pensarmos na proliferação de câmeras de segurança que nos tornam protagonistas em uma sociedade onde poderíamos querer ser apenas desconhecidos. Isso se agrava ainda mais com a criação de câmeras inteligentes. Estas, por estarem interligadas em rede na internet e por fazerem uso de inteligência artificial (I.A.), podem monitorar e fazer o reconhecimento facial de todas as pessoas que tiverem suas informações alocadas dentro de bancos de dados.

Nota-se que o sistema de vigilância continua prevalecendo, mas agora operando de um modo diferente. 0 mecanismo do Panóptico, tão caro para Foucault, dá lugar a outro: o do banco de dados. Este seria uma espécie de versão digital do Panóptico, que tem como característica peculiar o fato de operar sem a necessidade de uma estrutura arquitetônica que prenda e encerre os corpos dos indivíduos. 0 Panóptico tinha como propósito instituir a disciplina como forma de moldar padrões e evitar variações de comportamento e

\footnotetext{
${ }^{12}$ DELEUZE, Qu'est-ce que l'acte de création?, 300, tradução nossa.

${ }^{13}$ DELEUZE, Conversações, 216.
} 
subjetividades. Já o objetivo do banco de dados é conferir credibilidade às pessoas cadastradas para garantir sua confiabilidade.

O Panóptico laçava seus internos como produtores e/ou soldados, dos quais se esperava e exigia uma conduta monótona e rotineira; o banco de dados registra os consumidores confiáveis e dignos de crédito, eliminando todo o restante que não deve ser levado em conta no jogo do consumo simplesmente pelo fato de não haver nada a registrar sobre suas atividades. A principal função do Panóptico era garantir que ninguém pudesse escapar do espaço estreitamente vigiado; a principal função do banco de dados é garantir que nenhum intruso entre aí sob falsas alegações e sem credenciais adequadas. Quanto mais informação sobre você contenha o banco de dados, mais livremente você poderá se movimentar ${ }^{14}$.

Na sociedade de controle a gestão da vida pública e democrática faz uso de dispositivos tecnológicos, software e algoritmos como ferramentas constituintes do jogo de poder da nova forma de governar contemporânea. Ao fomentar e instigar o livre uso das redes virtuais, e com serviços muitas vezes "gratuitos", estão ao mesmo tempo coletando dados de cada um de seus usuários mantendo assim seu arsenal de informação sempre repleto e atualizado. Conteúdo virtual com a capacidade de influenciar e afetar todos os campos de nossas vidas. Vamos tomar o caso dos algoritmos. Como toda invenção humana guarda nele mesmo as intenções de seus criadores. Como em sua grande maioria são criados por empresas e corporações são estas, então, que possuem os maiores bancos de dados sobre bilhões de usuários que fazem uso da internet. Como toda tecnologia ele deve parecer mais eficaz à medida que parecer ser mais neutro, completamente adequado e submetido aos interesses de seus compradores ${ }^{15}$.

Atenta a esse cenário das transformações tecnológicas digitais, e retomando o conceito de governamentalidade foucaultiana, a filósofa do Direito Antoinette Rouvroy cunhou o conceito de governamentalidade algorítmica ${ }^{16}$. Suas pesquisas têm o objetivo de buscar comprovar a ideia de que atualmente está em processo a instalação de um tipo completamente novo de governamentalidade que não se fundamenta tanto na lei ou na disciplina, mas sobre a otimização algorítmica dos comportamentos, das relações sociais e da própria vida dos indivíduos. Com efeito, a especificidade da governamentalidade algorítmica, reside no fato de que se baseia não mais sobre normas impostas pelo Estado. Seu fundamento está nos inúmeros vestígios numéricos de nossas atitudes e comportamentos que constantemente proliferam no mundo digital da internet (muitas vezes, e em geral, sem o nosso conhecimento).

[Trata-se de] um modo de governo alimentado essencialmente por dados brutos (que operam como sinais infra-pessoais e a-significantes, mas quantificáveis); que afetam os indivíduos sob o modo de alerta, provocando o reflexo, mais do que sob o modo da autorização, proibição ou persuasão, ao se apoiar sobre suas capacidades de entendimento e de vontade; visando essencialmente a antecipar o futuro, a limitar o possível, muito mais do que regulamentar as condutas. Os dispositivos da governamentalidade algorítmica integram o datamining: a exploração das reservas de dados massivos e brutos,

\footnotetext{
14 BAUMAN, Globalização: as consequências humanas, 59, destaque nosso.

15 SILVEIRA, Governo dos algoritmos, 272.

${ }^{16}$ Este termo foi usado pela primeira vez por Antoinette Rouvroy e Thomas Berns no texto "Gouvernementalité algorithmique et perspectives d'émancipation: le disparate comme condition d'individuation par la relation?", Révue Réseaux, v. 01, no 177, 2013, p. 163-196. A tradução brasileira foi publicada em 2015 na revista EcoPós, v.18, no02, p.36-56 (Acesso em: https://revistas.ufrj.br/index.php/eco pos/article/view/2662/2251). Essa mesma tradução, feita por Pedro Henrique Andrade, foi novamente publicada em: BRUNO, Fernanda et al. (orgs.). Tecnopolíticas da vigilância: perspectivas da margem. São Paulo: Boitempo, 2018, pág. 107-139.
} 
que individualmente não possuem nenhum sentido, para a partir deles traçar perfis de comportamento. 0 datamining permite gerir as pessoas de maneira personalizante, industrial, sistemática e preemptiva, se interessando por elas somente enquanto pertencentes a uma multitude de perfis (de consumidores, de delinquentes potenciais, etc) ${ }^{17}$.

Aqui vemos, em linhas gerais, um esboço dos principais pontos que devem ser analisados para o entendimento da governamentalidade algorítmica. 0 ponto de partida e a matéria-prima de todo planejamento e ação desta maneira de governar passa antes de tudo pelo imenso conjunto de dados digitais que formam o Big Data e do tratamento e uso desses por algoritmos cada vez mais inteligentes e autônomos. A recente e vertiginosa proliferação dos dados numéricos tem conduzido a uma radical mudança na maneira como são tratados e usados por administradores públicos e privados. 0 antigo sonho de um controle total da cidade e de seus habitantes ganha cada vez mais concretização através das chamadas smart cities (cidades inteligentes). A noção de smart city é algo em processo de elaboração e de implementação em diversos países. Ela ganhou contornos mais definidos quando a ideia de "Internet das Coisas" (IoT) passou a ser uma realidade ao transformar a experiência com o universo digital. A digitalização e a conexão global ultrapassaram as telas de computadores e smartphones e, paulatinamente, têm se estendido para as coisas em geral e para o espaço urbano.

Em suma, a cidade inteligente nasce da possibilidade de grandes volumes de dados serem produzidos incessantemente por seus habitantes, infraestruturas e serviços, por meio de uma arquitetura de rede de conexão sem fio abarcante e fiável, etiquetas digitais geolocalizadas disseminadas nos mais variados objetos, sistemas de filtragem e tratamento de fluxo de dados e uso de realidade aumentada visando oferecer uma experiência contextual enriquecida ${ }^{18}$.

Contudo, apesar dos benefícios e das promessas de eficiência e rapidez de um mundo extremamente conectado, é preciso realizar a devida crítica ao perigo que esse sonho de uma cidade inteligente e governada por algoritmos representa para nossa liberdade. Por um lado, quanto mais informações disponibilizamos por meio de nossos dados, mas nos tornamos transparentes para os sistemas digitais que "facilitam" nossas vidas. Por outro lado, também somos mais conhecidos nos mínimos detalhes e, cada vez mais, os algoritmos serão capazes de antecipar nossas condutas, oferecer serviços e conduzir nossas ações. Entretanto, seria equivocado achar que nos é oferecido aquilo que queremos pois

Não se trata de simplesmente dar às pessoas o que elas querem, mas sim de fazer com que se queira isso ou aquilo. No mundo administrado, o sujeito é objetificado e não livre. Em suma, é preciso que o sujeito acredite que quer realmente aquilo que se quer que ele queira. E com os novos recursos, o sujeito parece tornar-se ainda mais débil, incapaz de raciocinar e deliberar por conta própria, sendo facilmente levado (sem que ele se dê conta disso) na direção que se deseja ${ }^{19}$.

Em um contexto normal são oferecidas experiências ou produtos que achamos que irão melhorar a nossa vida cotidiana. No entanto, no contexto da pandemia de Covid-19, o que desejamos de forma imediata é que não sejamos contaminados por um vírus altamente mortal. Queremos estar protegidos de todo risco e perigo de ser infectado ou possivelmente morrer, o que nos impele a aceitar as recomendações colocadas pelos especialistas em saúde e

\footnotetext{
17 ROUVROY, Le gouvernement algorithmique ou l'"art" de ne pas changer le monde, 86, tradução nossa.

18 ALVES, Cidade inteligente e governamentalidade algorítmica, 231-232.

${ }^{19}$ ALVES, Cidade inteligente e governamentalidade algorítmica, 246-247.
} 
as regras implementadas pelas autoridades sanitárias e políticas. É nesse cenário de crise sanitária e de pandemia mundial que devemos pensar o uso feito pelo conjunto de dispositivos e das tecnologias digitais.

No atual modelo de quarentena da hiperconexão do infectado ainda se faz uso de técnicas usadas nos modelos de exclusão do leproso e de inclusão do pestífero. Diversas práticas antigas continuam sendo implementadas como: do isolamento de quem se contamina, das ações constantes de higienização, do estabelecimento de zonas seguras e de distanciamento social, da proibição de deslocamentos ou do fechamento de fronteiras entre os países, os estados e as cidades. Entretanto, mesmo que o indivíduo infectado rompa as barreiras de isolamento e circule ele é vigiado e controlado quanto ao distanciamento que mantém em relação a outras pessoas, quanto a sua temperatura corporal, quanto à rede de outros indivíduos com os quais manteve contato. As pessoas, os espaços e a circulação são monitorados, através dos registros de dados obtidos por meio de aplicativos e das redes digitais, pelo poder médico e político, dentro ou fora das residências.

Se antes da instalação do estado de pandemia mundial, devido ao alastramento do vírus causador da Covid-19, as nossas vidas já eram impactadas pela disseminação e uso de sistemas digitais, agora esse uso ganha dimensões estratosféricas. 0 rastreamento tem sido feito sobre todos os indivíduos, mas principalmente sobre aqueles que exercem funções e atividades essenciais - e que circulam - compõem o grupo dos mais vigiados. Quem fica em casa também é controlado não só sobre seu trabalho remoto, mas também quanto ao que consome ou o que faz para se divertir; se sai de casa há um complexo sistema de cruzamento de dados de GPS e de redes conectadas de wifi que podem determinar com exatidão sua localização. Isso porque ou estamos sempre com nossos celulares conectados à redes de internet ou existem câmeras de segurança ligadas a uma rede de informações.

Ao que tudo indica os países asiáticos souberam controlar melhor a epidemia de coronavírus do que países europeus e americanos ${ }^{20}$. Segundo algumas análises diversos fatores diferenciam países como China, Coréia do Sul e Japão de países como Itália, Espanha e Estados Unidos quanto ao combate ao coronavírus. Aliado à aplicação de quarentenas, o estabelecimento de isolamento social e a administração do tratamento médico possível também foi feito o uso em massa do big data e da vigilância digital. É o que pensa, por exemplo, o filósofo sul-coreano Byung-Chul Han quando afirma que

[...] para enfrentar o vírus os asiáticos apostam fortemente na vigilância digital. Suspeitam que o big data pode ter um enorme potencial para se defender da pandemia. Poderíamos dizer que na Ásia as epidemias não são combatidas somente pelos virologistas e epidemiologistas, e sim principalmente pelos especialistas em informática e macrodados. Uma

\footnotetext{
20 Contudo, apesar de países asiáticos, como a China, terem sido os primeiros a tomarem medidas médicas, sanitárias e políticas contra o novo coronavírus, e o terem controlado, não estão imunes a uma nova onda do vírus. Em relatório do dia 14/06/2020 divulgado pela Organização Mundial da Saúde (OMS) foi divulgado que após 56 dias sem nenhum novo caso confirmado de Covid-19 a cidade de Pequim registrou um caso de infecção local. 0 mesmo relatório informava que entre os dias 11 e 14 de junho foram confirmados 77 novos casos sintomáticos confirmados por testes laboratoriais em Pequim. Também foram identificados 46 novos casos confirmados em laboratório que foram descobertos após a identificação de 06 casos de sintomas gripais ligados ao Mercado de Xinfadi, em Pequim (WORLD HEALTH ORGANIZATION Coronavirus disease (Covid-19): Situation Report $\left.n^{\circ} 146,02\right)$. Após dois meses de um lento processo de controle do vírus e preparação para retomada das rotinas diárias os moradores de Pequim se viram retornando à uma situação muito próxima do que viveram em fevereiro de 2020, quando do estágio mais crítico da pandemia na cidade. A implantação de bloqueios, a exigência de isolamento social e o rígido controle sobre o deslocamento das pessoas foram novamente retomados. 0 caso de Pequim exemplifica que, apesar de todo aparato tecnológico e do uso de sistemas interligados de rastreamento digital, a capacidade de mutação do vírus Sars-Cov-2 somado às suas características de transmissibilidade ainda impedem um maior controle das taxas de infecção (RAGHAV, In Beijing it looked like coronavirus was gone. Now we're living with a second wave).
} 
mudança de paradigma da qual a Europa ainda não se inteirou. Os apologistas da vigilância digital proclamariam que o big data salva vidas humanas 21 .

Refletindo no momento em que a Covid-19 está longe de ter uma cura Han chega mesmo a dizer que entre o coletivismo oriental e o individualismo europeu o primeiro foi mais eficaz no combate ao coronavírus. Seu argumento passa pela constatação de que o big data e a vigilância estatal são amplamente naturalizados no Oriente, ao ponto em que na China existam mais de 200 milhões de câmeras de vigilância, sendo muitas munidas da técnica de reconhecimento facial. Estas câmeras dotadas de inteligência artificial podem observar e avaliar qualquer pessoa onde quer que vá nos espaços públicos: nas ruas, nas lojas, nas estações de metrô, nos aeroportos. Sua aposta é que

[...] o big data é mais eficaz para combater o vírus do que os absurdos fechamentos de fronteiras que estão sendo feitos nesses momentos na Europa. Graças à proteção de dados, entretanto, não é possível na Europa um combate digital do vírus comparável ao asiático. Os fornecedores chineses de telefonia celular e de Internet compartilham os dados sensíveis de seus clientes com os serviços de segurança e com os ministérios de saúde. O Estado sabe, portanto, onde estou, com quem me encontro, o que faço, o que procuro, em que penso, o que como, o que compro, aonde me dirijo. É possível que no futuro o Estado controle também a temperatura corporal, o peso, o nível de açúcar no sangue etc. Uma biopolítica digital que acompanha a psicopolítica digital que controla ativamente as pessoas ${ }^{22}$.

Essas análises, que certamente podem soar sombrias quanto a um futuro próximo, na verdade podem servir de alerta e nos colocar em estado de atenção quanto a possíveis tentativas de extração ilegal de dados pessoais. Entretanto, essa lógica de extração de dados que alimentam de informações as administrações governamentais têm se tornado, há muito tempo, uma realidade. Tanto que, na atual pandemia de Covid-19, muitos dados de saúde pessoais são coletados e usados por governos em diversos países para tomar as decisões médicas e políticas mais acertadas. Aprofundamos ainda mais a vigilância sobre os corpos ao passarmos de um controle sobre a pele para um controle sob a pele.

\section{Considerações finais}

A relação entre a quarentena e o panóptico segue uma lógica semelhante. A primeira visa o controle declarado e generalizado de uma população presa em um território fechado. 0 segundo monitora os gestos e movimentos dos indivíduos sem que esses saibam quando e em que momento isso é feito. Nelas existem duas maneiras e duas práticas diferentes de exercício do poder político disciplinar e de vigilância: a quarentena é o controle público, possivelmente militar, do espaço de uma multidão anônima; a prisão panóptica é o controle oculto e contínuo dos comportamentos singulares de um grupo restrito e bem definido de indivíduos.

Em síntese, o dispositivo panóptico antecipa o inventário de técnicas de controle contemporâneas. Estas, fazendo uso de sistemas eletrônicos e dispositivos digitais silenciosos, se fazem de modo sutil e sem uso de violência corporal. 0 que não significa serem menos invasivas. Pelo contrário, o complexo mecanismo que conjuga a big data, a digitalização da vida, o governo digital, os algoritmos, a internet das coisas e outras técnicas e ferramentas digitais são muito mais agressivas porque são capazes de estabelecer um controle efetivo sobre nossas mentes e subjetividades. E, por elas, direcionar e conduzir nossos corpos, nossas vontades e nossos desejos.

${ }^{21}$ HAN. O coronavírus de hoje e o mundo de amanhã.

22 HAN. $O$ coronavírus de hoje e o mundo de amanhã. 
Existe uma mudança no nosso sentido de liberdade. Parece que estamos vivenciando atualmente uma noção de liberdade que se encontra na fronteira entre uma liberdade ligada à privacidade e ao privado e uma liberdade da hiperconexão digital - a sendo esta última cheia de armadilhas. Armadilhas porque aquilo que nos dá acesso e amplia nossa margem de ação de escolha é, ao mesmo tempo, aquilo que nas cerceia e que nos vigia. Um conceito que está sendo usado, no campo da segurança, neste momento de pandemia do novo coronavírus é o de vulnerabilidade. Esse conceito trabalha com a aceitação de nossos limites e dos limites dos outros. Esse mesmo conceito pode ser usado para pensar uma nova ideia de liberdade em um contexto de hiperconexão.

Talvez essa situação de pandemia nos possibilite colocar novamente e de forma mais consistente a questão dos limites e das responsabilidades. Talvez devamos repensar se não extrapolamos os limites: seja em nossas relações sociais, seja nos sistemas de distribuição de renda, seja nos limites do uso que fazemos de nosso planeta, seja quanto ao uso das tecnologias digitais, seja sobre os limites da biotecnologia, seja para com os usos futuros da inteligência artificial. Ao pensar o pós-Covid-19 não podemos desejar "uma volta a nossas vidas normais". Uma volta à normalidade parece ser o desejo de voltar aos mesmos erros realizados antes desse evento de pandemia. Existem promessas de um mundo futuro diferente. Existem razões para o querer. Mas a possibilidade do acirramento de conflitos, do surgimento de nacionalismos extremos, do aprofundamento de desigualdades sociais, de intensificação da digitalização de nossas vidas, entre outras coisas, é muito grande. Resta ficarmos atentos e trabalharmos para sairmos melhores dessa experiência. Veremos!

\section{Referências}

ALVES, Marco Antônio Sousa. Cidade inteligente e governamentalidade algorítmica: liberdade e controle na era da informação. Philósophos - Revista de Filosofia, Goiânia, vol. 23, no 02, jul./dez. 2018, p. 177-213.

BAUMAN, Zygmunt. Globalização: as consequências humanas. Rio de Janeiro: Jorge Zahar, 1999.

CANDIOTTO, César. Entrevista: Foucault e a governamentalidade biopolítica. In: Revista do Instituto Humanitas Unisinos, edição 324, 12/04/2010. Disponível em: http://www.ihuonline.unisinos.br/artigo/3127-cesar-candiotto-1. Acessado em: $27 / 06 / 2020$.

DELEUZE, Gilles. Controle e devir. In: DELEUZE, Gilles. Conversações, 1972-1990. São Paulo: Editora 34, 1992, p. 209-218.

DELEUZE, Gilles. Qu'est-ce que l'acte de création? In: DELEUZE, Gilles. Deux régimes de fous. Paris: Les Éditions de Minuit, 2003, p. 291-302.

FOUCAULT, Michel. Vigiar e Punir: nascimento da prisão. 42 $2^{\text {a }}$ edição. Petrópolis, RJ: Vozes, 2014.

FOUCAULT, Michel. Os anormais: curso no Collège de France (1974-1975). São Paulo: Martins Fontes, 2001.

HAN, Byung-Chul. O coronavírus de hoje e o mundo de amanhã. In: Jornal El País, 22/03/2020. Disponível em: <https://brasil.elpais.com/ideas/2020-03-22/o-coronavirus-de-hoje-e-omundo-de-amanha-segundo-o-filosofo-byung-chul-han.html?rel=mas $>$. Acessado em 26/04/2020.

RAGHAV, Krish. In Beijing it looked like coronavirus was gone. Now we're living with a second wave. In: The Guardian, 21/06/2020. Disponível em: 
https://www.theguardian.com/commentisfree/2020/jun/21/beijing-coronavirus-secondwave-virus-china. Acessado em: 27/06/2020.

RICHARDS, Peter. The Medieval Leper and his Northern Heirs. Cambridge: D.S. Brewer, 2000.

ROUVROY, Antoinette. Le gouvernement algorithmique ou l'"art" de ne pas changer le monde: les (n)ombres ou la vie. Draft / Version provisoite, 23/11/2016. Disponível em: https://www.academia.edu/30054245/Le gouvernement algorithmique ou 1 art de ne pas changer le monde. Les $n$ ombres ou la vie?auto=download Acessado em 26/04/2020.

SILVEIRA, Sérgio Amadeu. Governo dos algoritmos. Revista de Políticas Públicas da UFMA, volume 21, número 01, 2017, p. 267-281.

WORLD HEALTH ORGANIZATION. Coronavirus disease (Covid-19): Situation Report no 146, 14/06/2020. Disponível em: https://www.who.int/docs/defaultsource/coronaviruse/situation-reports/20200614-covid-19-sitrep-

146.pdf?sfvrsn=5b89bdad 6. Acessado em: 27/06/2020. 